\title{
Maternal outcome in term premature rupture of membranes
}

\author{
Amulya M. N., Ashwini M. S.*
}

Department of Obstetrics and Gynecology, Shimoga Institute Medical Science, Shimoga, Karnataka, India

Received: 03 December 2018

Accepted: 29 December 2018

*Correspondence:

Dr. Ashwini M. S.,

E-mail: ashwini.mallesara@gmail.com

Copyright: () the author(s), publisher and licensee Medip Academy. This is an open-access article distributed under the terms of the Creative Commons Attribution Non-Commercial License, which permits unrestricted non-commercial use, distribution, and reproduction in any medium, provided the original work is properly cited.

\section{ABSTRACT}

Background: Rupture of Fetal membranes before the onset of labour is called PROM. Premature rupture of membrane (PROM) is associated with various complications. The present study is undertaken to study the maternal morbidity in term PROM.

Methods: A prospective cross-sectional study was conducted at Vijaynagar institute of medical science Ballari for a period of one year by Department of Obstetrics and Gynecology from November 2016 to October 2017. 120 cases of spontaneous rupture of membranes with term gestation with confirmed PROM were selected.

Results: PROM was common in age group of 20-29 years (80\%), and common in primigravida. Study showed majority of them belongs to low socioeconomic status $(80 \%), 13.33 \%$ belonged to middle socioeconomic status and $6.66 \%$ belonged to higher socioeconomic status. In present study, it is observed that $27.05 \%$ cases went into spontaneous labour and delivered normally, $56.50 \%$ cases delivered by induction and $20 \%$ cases were delivered by LSCS. The rate of maternal morbidity was $16.6 \%$, which includes febrile morbidity accounting to maximum with 9.6\% followed by wound infection $3.33 \%$ and others were $\mathrm{PPH}(1.66 \%$ )and puerperal sepsis (each $1.66 \%)$.

Conclusions: The rate of maternal morbidity was $16.6 \%$ and no maternal death observed. Hence an appropriate and accurate diagnosis of PROM is essential for favorable outcome in pregnancy and reduces the maternal morbidity.

Keywords: LSCS, Maternal morbidity, Premature rupture of membrane

\section{INTRODUCTION}

Membranes rupture usually occurs during active phase of normal labour. Early rupture of membranes contributing to significant maternal and perinatal morbidity. However, the risk is more with multiple factors like duration of pregnancy and time of rupture of membranes. ${ }^{1}$

The management of premature rupture of membranes has gone through various cycles of obstetric activity from neglect to immediate intervention. Paralleling these cycles of activity there have been varying degrees of concern about infection According to some studies incidence of premature rupture of membranes is around $5-10 \% .^{2}$ The time from the rupture of membranes to the onset of contraction is defined as the latent period. The key factor in the fetal and maternal outcome is that the diagnosis of pre-labour rupture of membranes must be established. In most instances either it is obvious from the escape of clear amniotic fluid from cervix or by simple laboratory test like detection of fern pattern/Litmus paper test.

The key to the management is an accurate assessment of gestational age and the presence or absence of chorioamnionitis. Complications such as intra-amniotic infection occurs in 13\%-60\% of women with PROM, placental abruption, and postpartum endometritis.3,4 Patients with PROM are more prone to ascending infection, longer the time duration between rupture of membranes and onset of labour, more will be the risk of ascending infection and acquiring chorioamnionitis. ${ }^{5}$ 
Chorioamnionitis, dysfunctional labour, increased cesarean rates, postpartum hemorrhage and endometritis increases with PROM. Management is not clear, the main uncertainly relating to induction of labour or expectant care.

Three decades ago the main worry of premature rupture of the membranes was intra uterine infection and this led the wide spread absorption of a policy of induction of delivery to prevent such infection.

This view has challenged by an apparent increase in the number of caesarean section in woman with premature rupture of the membranes who had their labour induced. Hence PROM is an obstetric condition associated with significant maternal morbidity and mortality. ${ }^{6}$ Hence the present study was conducted to analyze the maternal outcomes in premature rupture of membranes at term.

\section{METHODS}

A prospective cross-sectional study was conducted at Vijaynagar institute of medical sciences, Ballari for a period of 1 year by Department of Obstetrics and Gynecology from November 2016 to October 2017.

All patients attending the outpatient department and causality with history of leak PV were admitted and were enrolled as cases in the study. All cases were examined in detail and confirmed by per speculum examination and ultrasonography.

A detailed history of leak per vagina, menstrual and obstetric history obtained by questioning and detailed clinical obstetric examination was done.

Condition of vagina and cervix was noted by speculum examination. Cervical swab was taken and sent for gram stain and culture and sensitivity.

\section{Inclusion criteria}

- Singleton pregnancy more than 37 weeks of gestation.

- Includes both Primi and multi gravida.

- Age group 18-40 years.

- Leaking from cervix confirmed by speculum examination.

- Cervix dilatation less than $3 \mathrm{~cm}$.

- Lack of uterine contractions.

\section{Exclusion criteria}

- Multiple pregnancies.

- Maternal complications interfering with active management of PROM like PIH, heart disease, previous LSCS, GDM.

- Immunocompromised cases including HIV, $\mathrm{HBsAg}$ positive cases.

\section{RESULTS}

The age group range in the study was 18-40 yeas, according to the incidence of age in PROM the most common age group in the study was 20-29 years $(81.66 \%)$ followed in order by age less than $20(12.5 \%)$ and $30-40$ years $(5.83 \%)$ (Table 1$)$.

Table 1: Age incidence in PROM.

\begin{tabular}{|l|l|l|}
\hline Age in years & No. of cases & Percentage \\
\hline$<20$ & 15 & 12.5 \\
\hline $20-29$ & 98 & 81.66 \\
\hline $30-40$ & 7 & 5.83 \\
\hline Total & 120 & 100 \\
\hline
\end{tabular}

Study showed majority of them belong to low socioeconomic status (80\%), $13.33 \%$ were belonging to middle socioeconomic status and $6.66 \%$ were belonging to higher socioeconomic status (Table 2).

Table 2: Socio-economic status in PROM.

\begin{tabular}{|l|l|l|}
\hline SE class & No. of cases & Percentage \\
\hline Low (IV and V) & 96 & 80 \\
\hline Middle (III) & 16 & 13.33 \\
\hline High & 8 & 6.66 \\
\hline Total & 120 & 100 \\
\hline
\end{tabular}

Out of 120 cases 49 were booked $(40.82 \%)$, and 71 cases $(59.16 \%)$ were not booked. This does not have any impact on antenatal care and incidence of PROM in the study result (Table 3).

Table 3: Antenatal care and PROM.

\begin{tabular}{|l|l|l|}
\hline An. booking & No. of cases & Percentage \\
\hline Booked & 49 & 40.83 \\
\hline Unbooked & 71 & 59.16 \\
\hline Total & 120 & 100 \\
\hline
\end{tabular}

According to the parity incidence $71.16 \%$ of cases were primigravidas, $19.16 \%$ were 2 nd gravida, $5.83 \%$ were 3 rd gravida and $3.33 \%$ of cases were 4 th gravida (Table 4 ).

Table 4: Parity incidence in PROM.

\begin{tabular}{|l|l|l|}
\hline Parity & No. of cases & Percentage \\
\hline G1 & 86 & 71.16 \\
\hline G2 & 23 & 19.16 \\
\hline G3 & 07 & 5.83 \\
\hline G4 & 04 & 3.33 \\
\hline
\end{tabular}

In 71 cases $(59.16 \%)$ cause was unknown, whereas 19 cases $(15.83 \%)$ showed it was due to infections, history of coitus was in 22 cases $(18.33 \%)$ and mal presentation in 8 cases $(6.66 \%)$ (Table 5). Out of 120 cases, 19 cases $(15.83 \%)$ has positive cervical swab culture. 
Table 5: Aetiological Analysis in PROM.

\begin{tabular}{|l|l|l|}
\hline Cause & $\begin{array}{l}\text { No. of positive } \\
\text { cases }\end{array}$ & Percentage \\
\hline Infection & 19 & 15.83 \\
\hline H/O coitus & 22 & 18.33 \\
\hline Mal-presentation & 8 & 6.66 \\
\hline H/O cervical surgery & 0 & 0 \\
\hline Not known & 71 & 59.16 \\
\hline Total & 120 & 100 \\
\hline
\end{tabular}

No bacterial growth was observed in 101 cases $(84 \%)$ in the study and the predominant isolate from the cervical swab was Escherichia coli 10 cases which accounts to $52.63 \%$ of 19 cases followed in order by Streptococci in 3 cases (15.78\%), Klebsiella pneumonia in 3 cases (15.78\%), Proteus in 2 cases $(10.52 \%)$ and Pseudomonas Aeruginosa in 1case (5.26\%) (Table 6).

\section{Table 6: Bacteriological study of amniotic fluid in} PROM.

\begin{tabular}{|l|l|l|}
\hline Organism grown & No. of cases & Percentage \\
\hline E. coli & 10 & 52.63 \\
\hline Streptococci & 3 & 15.78 \\
\hline Klebsiella & 3 & 15.78 \\
\hline Proteus & 2 & 10.52 \\
\hline Pseudomonas aeruginosa & 1 & 5.26 \\
\hline Total & 19 & 100 \\
\hline
\end{tabular}

In present study, it is observed that 33 cases $(27.05 \%)$ had gone for spontaneous labour and delivered normally, 63 cases $(56.50 \%)$ delivered by induction of labour and 24 cases $(20 \%)$ were delivered by LSCS (Table 7).

Table 7: Mode of delivery.

\begin{tabular}{|l|l|l|}
\hline Mode of delivery & No. of cases & Percentage \\
\hline Spontaneous labour & 33 & 27.5 \\
\hline Induction labour & 63 & 52.50 \\
\hline LSCS & 24 & 20 \\
\hline Total & 120 & 100 \\
\hline
\end{tabular}

The rate of maternal morbidity was $16.6 \%$ of which febrile morbidity accounting to maximum with 11 cases (9.6\%) followed by wound infection in 4 cases $(3.33 \%)$ and others were PPH and puerperal sepsis 2 cases each $(1.66 \%$ each) and clinical chorioamnionitis in 1 case $(0.83 \%)$ (Table 8$)$.

Table 8: Maternal morbidity in PROM.

\begin{tabular}{|l|l|l|}
\hline Morbidity & No. of cases & Percentage \\
\hline Febrile morbidity & 11 & 9.16 \\
\hline Clinical choriomnitis & 1 & 0.83 \\
\hline PPH & 2 & 1.66 \\
\hline Wound Infection & 4 & 3.33 \\
\hline Puerperal sepsis & 2 & 1.66 \\
\hline
\end{tabular}

\section{DISCUSSION}

PROM is a common complication of pregnancy which leads to increased maternal complications, operative procedures, maternal mortality and morbidity. In present study the commonest age group was 20-29 years (85\%) which correlates with the findings in the study of Kodkany BS et al and Devi A et al. ${ }^{7,8}$ PROM is more common in unbooked cases rather than booked cases and which is similar to findings in many studies all over the world. ${ }^{9}$

It is observed in present study that PROM was high in cases of low socioeconomic status $(80 \%)$ which might be due to many reasons like, poor nutritional status, anemia, and increased genitourinary infections due to poor personal hygiene, all these causes increased risk of PROM. Many studies reported low socioeconomic status associated with PROM. ${ }^{10}$

Study showed normal delivery is the commonest mode of delivery and the result is $80 \%$, which is similar to $\mathrm{V}$ Kamala et al study. ${ }^{11}$ LSCS rate in study group is $20 \%$, which is similar to Sita Ram Shreshta et al study. ${ }^{12}$ Ray P et al and Jayaram VK et al who reported an incidence of $31.5 \%$ of LSCS in their studies. ${ }^{11,13}$ In comparison to above mentioned 2 studies, rate of vaginal delivery was more in present study. This could be due to active management of labour, timely induction and augmentation, strict monitoring of fetal heart rate and judicial use of oxytocics, and instruments during delivery. In a study by Kshama Vishwakarma, Vaginal delivery was the commonest mode. Out of 347, 218 $(62.8 \%)$ women delivered vaginally, rest of women had caesarean section $(37.2 \%) .{ }^{14}$

Amniotic fluid culture is valuable for identifying the bacteria causing infection and their antibiotic sensitivity. The amniotic cavity generally is sterile. The term microbial invasion of the amniotic cavity refers to the presence of a positive amniotic fluid for microorganism's cultures, regardless of the presence or absence of clinical signs or symptoms of infection.

But $15.83 \%$ of patients in study group showed positivity in amniotic fluid culture and the predominant isolate from the cervical swab was Escherichia coli. In present study, the maternal mortality was nil, which was lower than that of $(0.26 \%)$ reported from Gujarat,India. ${ }^{15}$

The rate of maternal morbidity was $16.6 \%$ of which febrile morbidity accounting to maximum with $9.6 \%$ followed by wound infection $3.33 \%$ and others were $\mathrm{PPH}$ (1.66\%)and puerperal sepsis (each 1.66\%). In a similar study by Kshama Vishwakarma , there was some or other type of maternal morbidity in $14.9 \%$ cases (52 women in $347) ; 6.3 \%$ patients had wound infection, around $3 \%$ patients developed fever and abdominal distension, whereas $2.1 \%$ patients had symptoms of chorioamnionitis. ${ }^{14}$ In a study by Kadikar GK, Gandhi 
MR wound infection accounted for $03 \%$, maternal pyrexia accounted for $02 \%$, and UTI for $03 \%$ of cases. Chorioamnionitis was rare complication affecting only $1 \%$ of cases. ${ }^{16}$

\section{CONCLUSION}

The study shows majority of PROM patients were in age group of 20-29 years. There is significant correlation found between age group 20-29 and occurrence of PROM. The incidence of PROM was more in primigravida $(71.6 \%)$ than multigravida $(28.33 \%)$. Hence PROM is common in primigravida. Out of 120 cases 49 were booked $(40.82 \%)$, and only 71 cases $(59.16 \%)$ were not booked. This does not have any impact on antenatal care and incidence of PROM in the study result. The rate of maternal morbidity was $16.6 \%$ and no maternal death was observed. Hence an appropriate and accurate diagnosis of PROM is essential for favorable outcome in pregnancy and thus it decreases the maternal morbidity.

Funding: No funding sources

Conflict of interest: None declared

Ethical approval: The study was approved by the Institutional Ethics Committee

\section{REFERENCES}

1. Jairam VK, Sudha S. A study of premature rupture of membranes management and outcome. J Obstet Gynecol India. 2001;51(2):58-60.

2. Aktar MS, Degan JS, Aktar UA, D Sharam. PROM: Study of 300 cases and review of literature. J Obstet Gynecol India.1980;30:81.

3. ACOG Committee on Practice Bulletins-Obstetrics. ACOG Practice Bulletin No. 80: premature rupture of membranes. Clinical management guidelines for obstetrician-gynecologists. Obstet Gynecol 2007; 109:1007-10.

4. El-Messidi A, Cameron A. Diagnosis of premature rupture of membranes: inspiration from the past and insights for the future. J Obstet Gynaecol Can. 2010; 32(6):561-9.

5. Noor S, Nazar AF, Bashir R, Sultana R. Prevalance of PPROM and its outcome. J Ayub Med Coll Abbotta. 2008;19(4):14-17.
6. Naeye R, Peters E. Causes and consequences of premature rupture of fetal membranes. The Lancet. $1980 ; 315(8161): 192-4$.

7. Devi A, Rani R. Premature rupture of membranes- A clinical study. J Obstet Gynecol India. 1996;46:63.

8. Kodkany, Telang. Premature rupture of membranes, a study of 100 cases. J Obstet Gynecol India 1991;41:492.

9. El-Messidi A, Cameron A. Diagnosis of premature rupture of membranes: inspiration from the past and insights for the future. J Obstet Gynecol Can. 2010;32(6):561-9.

10. Vogel JP, Lee AC, Souza JP. Maternal morbidity and preterm birth in 22 low-and middle-income countries: a secondary analysis of the WHO Global Survey dataset. BMC Preg Childbirth. 2014;14(1):56.

11. Jayaram VK, Sudha S. A study of premature rupture of membranes- management and outcome. J Obstet Gynaecol India 2001;51(2):58-60.

12. Shrestha SR, Sharma P. Fetal outcome of pre-labor rupture of membranes. Nepal J Obstet Gynaecol. 2006;1(2):19-24.

13. Piya R, Sikdar K, Das A, Ghosh T. Study of cases of chorioamniotics followed premature rupture of membranes. J Obstet Gynecol India. 1997;47:136.

14. Kumar S. Impact of premature rupture of membranes on maternal and neonatal health in Central India. $\mathbf{J}$ Evidence Based Med Healthcare. 2015;2(48):8505-8.

15. Kassa EM, Sirak B. Maternal and perinatal outcome of pregnancies with preterm premature rupture of membranes (pprom) at tikur anbessa specialized teaching hospital, Addis Ababa, Ethiopia. Ethiopian Med J. 2015;52(4):165-72.

16. Gunvant KK, Gandhi MR, Damani SK. A Study of Feto- Maternal Outcome in Cases of Premature Rupture of Membrane. Int J Scienti Res.2014;3(3):817.

Cite this article as: Amulya MN, Ashwini MS. Maternal outcome in term premature rupture of membranes. Int J Reprod Contracept Obstet Gynecol 2019;8:576-9. 